\title{
A OCUPAÇÃO URBANA E A DINÂMICA COSTEIRA NA DESEMBOCADURA DO RIO SÃO MATEUS, CONCEIÇÃO DA BARRA - ES
}

\author{
Karla Nunes de Oliveira ${ }^{1}$ \\ Igor Bremenkamp Herzog ${ }^{2}$ \\ Juan Alfredo Ayala Espinoza ${ }^{3}$
}

Resumo: No ano de 2013 deu-se início ao desenvolvimento do projeto de extensão com número de registro SIEX 400556 intitulado "Estudo da efetividade de obras de contenção de erosão costeira em Conceição da Barra / ES”. Um dos objetivos é o estudo da morfologia dinâmica da linha costeira no setor de influências marinha e rio São Mateus utilizando-se técnicas de Sensoriamento Remoto -SR. Apesar das obras de contenção da erosão marinha ainda acontecem processos de erosão, levando a danos do patrimônio natural, ou seja, suas praias, e de infraestrutura urbanísticas e turística da cidade. $A$ análise temporal comparativa de imagens de satélite de diferentes datas mostrou que, o setor é altamente dinâmico, e que o avanço do desenvolvimento urbanístico sem nenhum plano municipal de desenvolvimento levou a serem ocupadas áreas de acomodação natural da linha de costa, hoje transformada as mesmas em uma extensão da cidade e consequentemente em áreas de risco, se tendo a destruição de casas e avenidas tanto no setor de praia marinha quanto no de rio. As técnicas de Sensoriamento Remoto, mostraram-se efetivas neste caso de estudo.

Palavras-chave: Dinâmica costeira; Sensoriamento remoto.

\footnotetext{
1 Universidade Federal do Espírito Santo/Departamento de Geologia, Brasil. E-mail: karlano766@gmail.com.

2 Universidade Federal do Espírito Santo/Departamento de Geologia, Brasil. E-mail: igorbherzog@hotmail.com.

3 Universidade Federal do Espírito Santo/Departamento de Geologia, Brasil. E-mail: juan.espinoza@ufes.br.
} 